\title{
On Studying the Inter-relationships Amongst the Various Driving Criteria for Studying the Driving Behavior in India
}

\author{
Yogender Singh \\ Aryabhatt College, \\ University of Delhi, \\ Delhi, India
}

\author{
V. K. Aggarwal \\ Recventures Education \\ Services Private Limited \\ Delhi, India
}

\author{
Lakshay Aggarwal \\ Recventures Education \\ Services Private Limited \\ Delhi, India
}

\author{
Remica Aggarwal \\ Recventures Education \\ Services Private Limited \\ Delhi, India
}

\begin{abstract}
Across all cultures and traditions, people describe spirituality as a dimension of experience that goes beyond the obvious way of perceiving reality as made up of separate physical objects. Buddhism talks about no-self or emptiness, while the Yogic tradition talks about true self or fullness. Abrahamic religions talk about the Creator or the Ground of Being. "Nonreligious but spiritual" people might talk about "Awareness," or nature, or Reality with a capital ' $R$ '. The truth is that all seem to point to a common unitive or absolute principle that goes beyond words and this common principle is always apprehended and expressed through the filter of the individual's unique culture and history with language and belief system. Present research work is an attempt to explore the spiritual meditation philosophy and thereafter studying the interrelationships amongst various challenges towards adoption of spiritual metrics due to nature of spirituality. These interrelationships have been study with the help of ISM methodology .
\end{abstract}

\section{Keywords}

Spiritual meditation philosophy ; Christianity ; Spiritual metrics; ISM Methodology

\section{INTRODUCTION}

Road safety has become a critical issue in emerging and developed countries. A comprehensive evaluation approach must be utilized to investigate the road safety issues due to risky driver behaviour. Driving behavior identification was considered the most important part in traffic studies to collect useful information generally in three main fields such as road safety analysis, microscopic traffic simulation and Intelligent Transportation Systems (ITS) [1]. Behavior identification was performed in different disciplines like psychology, physiology and ergonomics by taking natural data. The perspectives of human factors and vehicle dynamics application related to road safety were focused in the study [2]. A review of road safety models in outsourcing literature showed that many researches proposed approaches based on multi criteria decision making analysis to compute the road safety problems [3-6]. Some studies utilized a multi criteria decision making analysis for road safety performance evaluation [7]. The study focused on the fundamental factors solely related to road safety. It was observed that human factors contributes the most towards enhancing the impact on accident risk. The basic factors which directly influence on road safety were noticed such as driving behavior, driving experience and driver perception of traffic risks [8].

The study investigated that the task of driving can be easy or difficult depending on the momentary task demand of driving and the driver's skill to control his/her vehicle correctly. Experienced drivers were observed more apparent to show possible avoidance of traffic hazard by changing direction, speed, level of caution, center of attention and information communicated to other road users [9]. Road users' risk perception was found essential in the process of driving because it affects driving behavior [9]. The study investigated the most common causation elements such as faulty prediction or incorrect diagnosis. Automated driving systems are likely to solve the safety problems caused by those factors through perception and sensing technologies. However, risky factors such as unexpected road user behaviour, view obstructions and human error by other drivers still pose problems which need further measures to improve road safety [11]. Most of the previous studies focused only on evaluation of driver behaviour items related to road safety.

The study intended to highlight the most critical driver behaviour factors related to road safety. Thereafter, it studies the inter-relationships amongst them using ISM methodology. The paper is arranged as follows : Section 2 deals with literature review on various factors. Section 3 descries the ISM Methodology and section 4 describes the case example . Conclusions and managerial implications are present in section 5 .

\section{LITERATURE REVIEW}

Driver criteria analysis for road safety performance evaluation is performed by [7]. The study focused on the fundamental factors solely related to road safety. It was observed that human factors have the most considerable impact on accident risk.

2.1 Driver perception of traffic (DPT):The basic factors which directly influence on road safety were noticed such as driving behavior, driving experience and driver perception of traffic risks [8]. The survey study measured self-reported frequency of drivers involving in a range of driving attitudes and perceived risks.

2.2 Driving task experience [DTE] :Then there is a study by [12] that found that driving task experience has a statistically major effect on overall driving performance including overtaking and car speed. In fact, the professional drivers' have high driving time and mileage practice to generate better skills and knowledge of vehicle control [13]. The study found that the professional drivers drive more cautiously which was facilitated also by the demands of their work[14]. 


\subsection{Driver's careless behaviour [DCB] :} The study revealed that drivers with careless driver behavior, excessive speed, chronic fatigue and critical sleepiness may significantly increase the risk of road crashes which can lead to serious injuries [15].

2.4 High traffic volume flow [HTVF] : High traffic volume flow had a significant effect on vehicles conflicts because drivers are more likely to accept shorter gaps at unsignalized intersections [16].

\subsection{Road users' risk perception [ RURP]:}

This was found essential in the process of driving because it affects driving behavior[10]. The study investigated the most common causation elements such as faulty prediction or incorrect diagnosis.

\subsection{Unexpected road use behaviour}

[URUB] : Risky factors such as unexpected road user behavior, View obstructions and human error by other drivers [HE]: still pose problems which need further measures to improve road safety [11].

2.7 Poor visibility conditions [PVC] : Driving largely is a visual task. Poor visibility conditions such as rain, fog, or snow create several additional demands on the driver and their ability to collect necessary visual information is drastically reduced.

\subsection{Weather related conditions [WRC] :}

The driving task becomes more complex when weatherrelated conditions of reduced visibility are accompanied by wet surfaces. The review of related literature highlights that over the past couple of decades, international groups such as the Intergovernmental Panel on Climate Change (IPCC), and the Climate Change Science Program (CCSP) and Transportation Research Board (TRB) have done several studies that describe the details of climatic changes and their potential societal impacts,.

\subsection{Driver and roadway characteristics}

[DRWC] :The driving task involves performing a number of activities e.g. guiding the vehicle within the road, detecting other vehicles, non-motorized users, judging their speed, position, their possible behaviour and reacting accordingly [17].

\subsection{Miscellaneous conditions [ $\mathrm{MC}]$ :} Conditions such as wet pavement, impaired visibility, heavy precipitation, frozen precipitation, flooding, high winds, and extremes of temperature can act in various ways to increase risks to drivers and their vehicles, as well as the infrastructure.
2.11 Poor training of drivers [PTD]: A study done by [20]highlights that driver behaviour through better driver education, driver training and licensing procedures along with good on-road enforcement can be improved. The gamut of these researches helped to create the background of the present study under different Indian weather conditions.

\section{INTERPRETIVE STRUCTURAL MODELLING METHODOLOGY}

Interpretive structural modelling methodology or ISM [21] is a known technique to map the relationships amongst the relevant elements as per decision maker's problems in a hierarchical manner. Starting with the identification of elements, it proceeds with establishing the contextual relationships between elements (by examining them in pairs ) and move on towards developing the structural selfinteraction (SSIM) matrix using VAXO [21] and then initial reachability matrix and final reachability matrix and rearranging the elements in topological order using the level partition matrices. A Mic-Mac analysis is performed afterwards which categorize the variables as per the driving and dependence power in to autonomous, dependent, driver and linkage category. Finally, a diagraph can be obtained.

\section{DEVELOPMENT OF ISM MODEL : CASE EXAMPLE}

The 11 barriers viz. Driver perception of traffic (DPT); Driving task experience [DTE]; Driver's careless behaviour [DCB]; High traffic volume flow [HTVF] ; Road users' risk perception [ RURP]; Unexpected road use behaviour [URUB] ; Poor visibility conditions [PVC]; Weather related conditions [WRC]; Driver and roadway characteristics [DRWC]; Miscellaneous conditions [ MC]; Poor training of drivers [PTD] described in section 2 above have been studied further for the possible inter-relationship amongst them using ISM methodology

\subsection{Construction of Structural self- interaction Matrix (SSIM)}

This matrix gives the pair-wise relationship between two variables i.e. I and $j$ based on VAXO. SSIM has been presented below in Fig 1 .

\subsection{Construction of Initial Reachability Matrix and final reachability matrix}

The SSIM has been converted in to a binary matrix called the initial reachability matrix shown in fig. 2 by substituting V, A, $\mathrm{X}, \mathrm{O}$ by 1 or 0 as per the case. After incorporating the transitivity, the final reachability matrix is shown below in the Fig 3.

\begin{tabular}{|c|c|c|c|c|c|c|c|c|c|c|c|c|}
\hline $\begin{array}{c}\text { S. } \\
\text { No. }\end{array}$ & Barriers & 1 & 2 & 3 & 4 & 5 & 6 & 7 & 8 & 9 & 10 & 11 \\
\hline & & DPT & DTE & DCB & HTVF & RURP & URUB & PVC & WRC & DRWC & MC & PTD \\
\hline 1 & DPT & & A & V & V & A & V & A & A & V & A & O \\
\hline 2 & DTE & & & O & V & A & A & A & A & x & A & A \\
\hline 3 & DCB & & & & V & V & V & A & A & V & A & A \\
\hline 4 & HTVF & & & & & V & V & A & A & x & A & A \\
\hline 5 & RURP & & & & & & V & A & A & V & A & o \\
\hline 6 & URUB & & & & & & & A & A & x & A & A \\
\hline
\end{tabular}




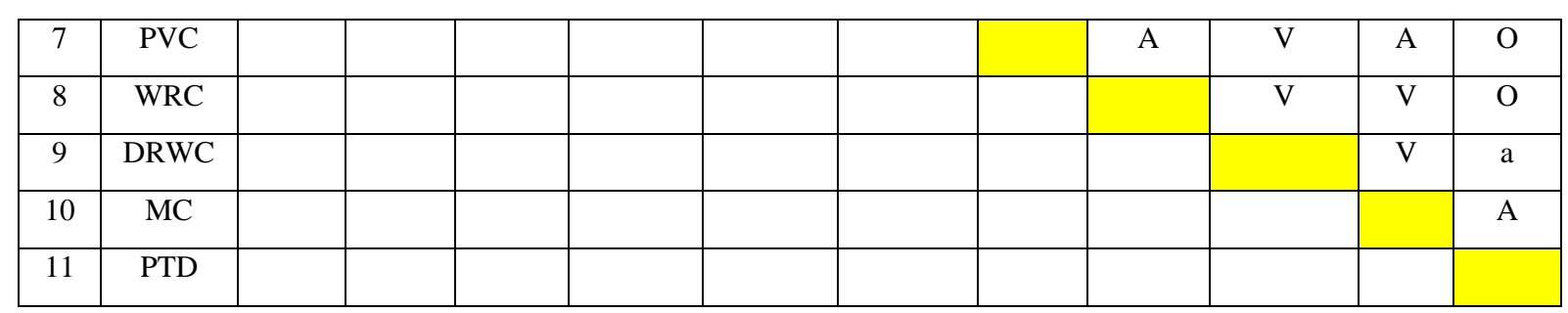

Fig 1: SSIM matrix for pair wise relationship amongst barriers

\begin{tabular}{|c|c|c|c|c|c|c|c|c|c|c|c|c|}
\hline $\begin{array}{c}\text { S. } \\
\text { No. }\end{array}$ & Barriers & 1 & 2 & 3 & 4 & 5 & 6 & 7 & 8 & 9 & 10 & 11 \\
\hline & & DPT & DTE & DCB & HTVF & RURP & URUB & PVC & WRC & DRWC & MC & PTD \\
\hline 1 & DPT & 1 & 0 & 1 & 1 & 0 & 1 & 0 & 0 & 1 & 0 & 0 \\
\hline 2 & DTE & 1 & 1 & 0 & 1 & 0 & 0 & 0 & 0 & 1 & 0 & 0 \\
\hline 3 & DCB & 0 & 0 & 1 & 1 & 1 & 1 & 0 & 0 & 1 & 0 & 0 \\
\hline 4 & HTVF & 0 & 0 & 0 & 1 & 1 & 1 & 0 & 0 & 1 & 0 & 0 \\
\hline 5 & RURP & 1 & 1 & 0 & 0 & 1 & 1 & 0 & 0 & 1 & 0 & 0 \\
\hline 6 & URUB & 0 & 1 & 0 & 0 & 0 & 1 & 0 & 0 & 1 & 0 & 0 \\
\hline 7 & PVC & 1 & 1 & 1 & 1 & 1 & 1 & 1 & 0 & 1 & 1 & 0 \\
\hline 8 & WRC & 1 & 1 & 1 & 1 & 1 & 1 & 1 & 1 & 1 & 1 & 0 \\
\hline 9 & DRWC & 0 & 1 & 0 & 1 & 0 & 1 & 0 & 0 & 1 & 0 & 0 \\
\hline 10 & MC & 1 & 1 & 1 & 1 & 1 & 1 & 1 & 0 & 1 & 1 & 0 \\
\hline 11 & PTD & 0 & 1 & 1 & 1 & 0 & 1 & 0 & 0 & 1 & 1 & 1 \\
\hline
\end{tabular}

Fig 2: Initial reachability matrix

\begin{tabular}{|c|c|c|c|c|c|c|c|c|c|c|c|c|c|}
\hline $\begin{array}{c}\text { S. } \\
\text { No. }\end{array}$ & Barriers & 1 & 2 & 3 & 4 & 5 & 6 & 7 & 8 & 9 & 10 & 11 & D.P \\
\hline & & DPT & DTE & DCB & HTVF & RURP & URUB & PVC & WRC & DRWC & MC & PTD & \\
\hline 1 & DPT & 1 & 1 & 1 & 1 & 1 & 1 & 0 & 0 & 0 & 0 & 0 & 6 \\
\hline 2 & DTE & 1 & 1 & 1 & 1 & 0 & 1 & 0 & 0 & 0 & 0 & 0 & 4 \\
\hline 3 & DCB & 0 & 1 & 1 & 1 & 1 & 1 & 0 & 0 & 0 & 0 & 0 & 4 \\
\hline 4 & HTVF & 0 & 1 & 0 & 1 & 1 & 1 & 0 & 0 & 0 & 0 & 0 & 3 \\
\hline 5 & RURP & 1 & 1 & 0 & 1 & 1 & 1 & 0 & 0 & 0 & 0 & 0 & 2 \\
\hline 6 & URUB & 0 & 1 & 0 & 1 & 0 & 1 & 0 & 0 & 0 & 0 & 0 & 1 \\
\hline 7 & PVC & 1 & 1 & 1 & 1 & 1 & 1 & 1 & 0 & 1 & 1 & 0 & 8 \\
\hline 8 & WRC & 1 & 1 & 1 & 1 & 1 & 1 & 1 & 1 & 1 & 1 & 0 & 10 \\
\hline 9 & DRWC & 0 & 1 & 0 & 1 & 0 & 1 & 0 & 0 & 1 & 0 & 0 & 4 \\
\hline 10 & MC & 1 & 1 & 1 & 1 & 1 & 1 & 1 & 0 & 0 & 1 & 0 & 8 \\
\hline 11 & PTD & 1 & 1 & 1 & 1 & 1 & 1 & 0 & 0 & 0 & 1 & 1 & 7 \\
\hline & De.P & 7 & 11 & 7 & 11 & 8 & 11 & 3 & 1 & 3 & 5 & 1 & \\
\hline
\end{tabular}

Fig 3 : Final reachability matrix

D.P :Driving power ; De.P : dependence power 


\section{RECOMMENDATIONS}

Traffic awareness in the community should be raised through mass media

- Traffic awareness among students should be raised through integration of the subject to the teaching curricula at different educational levels .

- Traffic laws should be strictly enforced, especially regarding the age of drivers. The penalties on the parents of children and adolescents who drives the cars before being eligible to hold a driving licence should be strengthened.

- Speed limits should be strictly monitored using sensitive modern equipment.

\section{ACKNOWLEDGEMENTS}

Author Remica Aggarwal is thankful to Prof. S,P Singh for disseminating the knowledge about ISM methodology which has helped her in writing this piece of work.

\section{REFERENCES}

[1] Bifulco, G. N., Galante, F., Pariota, L. 2014 .Data Collection for Traffic and Drivers' Behavior Studies: a large-scale survey", Procedia - Social and Behavioral Sciences, $\quad 111$, 721-730. https://doi.org/10.1016/j.sbspro.2014.01.106

[2] Plochl, M., Edelmann, J. 2007 . Driver models in automobile dynamics application, Vehicle System Dynamics, 45(7-8), 699-741. https://doi.org/10.1080/00423110701432482.[2

[3] Haghighat, F. 2011 . Application of a multi-criteria approach to road safety evaluation in the Bushehr Province, Iran", PROMET - Traffic \& Transportation, 23(5), 341-352. https://doi.org/10.7307/ptt.v23i5.152 .

[4] Hermans, E., Van den Bossche, F., Wets, G. 2008. Combining road safety information in a performance index . Accident Analysis \& Prevention, 40(4), 13371344. https://doi.org/10.1016/j.aap.2008.02.004

[5] Nanda, S., Singh, S. 2018. Evaluation of factors responsible for road accidents in India by Fuzzy AHP , In: Perez, G., Mishra, K., Tiwari, S., Trivedi, M. (eds.) Networking Communication and Data Knowledge Engineering, Lecture Notes on Data Engineering and Communications Technologies, 3, Springer, Singapore, 179-188. https://doi.org/10.1007/978-981-10-4585-1_15

[6] Shi, H. 2009. Fuzzy evaluation approach of road traffic safety based on AHP. In: 2009 International Conference on Future BioMedical Information Engineering (FBIE), Sanya, China, 394-397. https://doi.org/10.1109/FBIE.2009.5405832 .

[7] Bao, Q., Ruan, D., Shen, Y., Hermans, E. 2012. Improved hierarchical fuzzy TOPSIS for road safety performance evaluation", Knowledge-Based Systems, 32, 84-90. https://doi.org/10.1016/j.knosys.2011.08.014.

[8] De Oña, J., De Oña, R., Eboli, L. 2014.How to identify the key factors that affect driver perception of accident risk, A comparison between Italian and Spanish driver behavior", Accident Analysis and Prevention, 73, 225-

\section{5. https://doi.org/10.1016/j.aap.2014.09.020}

[9] Fuller, R. 2005.Towards a general theory of driver behavior", Accident Analysis \& Prevention, 37(3), 461472. https:/doi.org/10.1016/j.aap.2004.11.003

[10] Wang, B., Hensher, D. A., Ton, T. 2002 . Safety in the road environment: A driver behavioral response perspective", Transportation, 29(3), 253-270. https://doi.org/10.1023/A:1015661008598

[11] Sandin, J. 2009. An analysis of common patterns in aggregated causation charts from intersection crashes, Accident Analysis and Prevention, 41(3), 624-632. https://doi.org/10.1016/j.aap.2009.02.015

[12] Da Silva, F. P., Santos, J. A., Meireles, A. 2014.Road accident: Driver behavior, learning and driving task, Procedia - Social and Behavioral Sciences, 162, 300309. https://doi.org/10.1016/j.sbspro.2014.12.211

[13] Yan, X., Li, X., Liu, Y., Zhao, J. 2014 . Effects of foggy conditions on drivers' speed control behaviors at different risk levels", Safety Sciences, 68, 275-287. https://doi.org/10.1016/j.ssci.2014.04.013

[14] Öz, B., Özkan, T., Lajunen, T. 2010 . Professional and non-professional drivers' stress reactions and risky driving", Transportation Research Part F, 13, 32-40. https://doi.org/10.1016/j.trf.2009.10.001.

[15] Bener, A. B., Yildirim, E., Ozkan, T. 2017. Driver sleepiness, fatigue, careless behavior and risk of motor vehicle crash and injury: Population based case and control study", Journal of Traffic and Transportation engineering (English edition), 4(5), 496-502. https://doi.org/10.1016/j.jtte.2017.07.005

[16] Caird, J. K., Willness, C. R., Steel, P. 2008 .A metaanalysis of the effects of cell phones on driver performance", Accident Analysis and Prevention, 40(4), 1282-1293. https://doi.org/10.1016/j.aap.2008.01.009.

[17] Khattak, A.J.,Koppelman, F.S.,\& Schofer, Information and Implications for Information Systems. Proceedings of the 72nd annual meeting of the Transportation Research Board. Washington, DC: Transportation Research Board.

[18] Neelima Chakrabarty, Kamini Gupta 2013. Analysis of driver behaviour and crash characteristics during adverse weather conditions, Procedia Social and Behavioural Sciences 104; 1048-1057. 2013

[19] Vinand M Nantulya , Michael R Reich . The neglected epidemic : road traffic injuries in developing countries , BMJ. 2002: 324, 1139-1141.

[20] Verma, A., Velumurugan,S., Chakrabarty, N.\& Srinivas, S. 2011 .Recommendations for driver licensing and traffic law enforcement in India aiming to improve Road safety.Jr. of Current Science, 100(9).

[21] Warfield, J.N. 1974. Developing interconnection matrices in structural modeling. IEEE Transactions on Systems, Man, and Cybernetics, (1), 81-87. 